\title{
Acesso à informação e identidade cultural: entre o global e o local
}

Isa Maria Freire

Professora e pesquisadora

Instituto Brasileiro de Informação em Ciência e Tecnologia (Ibict).

Doutora em ciência da informação, UFRJ-Ibict

E-mail: isa@ibict.br

\section{Resumo}

Apresenta o quadro teórico e metodológico da pesquisa Janelas da Cultura Local, em implementação no Instituto Brasileiro de Informação em Ciência e Tecnologia com apoio do Conselho Nacional de Desenvolvimento Científico e Tecnológico, que tem como objetivo promover, de forma participativa, ações de informação no sentido da inclusão digital. As premissas do projeto - a informação como força de transformação, a responsabilidade social da ciência da informação e a sua relação intrínseca com a tecnologia da informação - se manifestam na proposta de desenvolvimento de competências para produção e comunicação digital da informação, contribuindo para dotar os participantes de elementos de mediação entre a cultura local e a cultura global. Espera-se, com o projeto, trazer contribuição ao resgate e registro da memória cultural da comunidade envolvida na pesquisa, contribuindo, também, para elevação do Índice de Desenvolvimento Humano no município beneficiado.

\section{Palavras-chave}

Inclusão digital. Identidade cultural. Gestão da informação. Responsabilidade social. Ciência da informação.

\section{Information access and cultural identity: between global and local}

\section{Abstract \\ It presents the theoretical and methodological framework of the research Local Cultural Windows being implemented at the Brazilian Institute for Information in Science and Technology with the sponsorship of the National Counsel for Scientific and Technological Development, which aims to stimulate, in a participative way, information actions to promote digital inclusion. The premises of the project - information as a transformation strength, the social responsibility of Information Science and its intrinsic relation to information technology - emerge in the proposal as the development of the competencies required for the production and communication of information in digital media, thus contributing to enable the participants to navigate between the local and the global cultures. With this project we aim to redeem and register the cultural memory of the community the research focus at and to contribute to enhance the Human Development Rates of the city under study.}

\section{Keywords}

Digital inclusion. Cultural identity. Information management. Social responsibility. Information science.

\section{INTRODUÇÃO}

Na sociedade contemporânea, a comunicação mediada por computadores interligados em rede gera grande diversidade de comunidades virtuais, caracterizando a metáfora da "aldeia global", conforme observamos em Ianni: "Províncias, regiões e nações, bem como culturas e civilizações, são atravessadas e articuladas pelos sistemas de informação e comunicação" (IANNI, 1997, p.228). Segundo o autor, neste espaço social ocorre um processo de difusão de padrões culturais globais que acarretam alienação dos valores e das culturas locais.

Analisando os fatores que podem caracterizar uma crise das identidades no processo de globalização, Hall (1998) sugere que esta pode ser consoante com as concepções de identidade cultural formuladas em torno do papel que o sujeito social adquiriu nas transformações históricas recentes da humanidade. $\mathrm{Na}$ concepção iluminista, o indivíduo era dotado das capacidades de razão, de consciência e de ação, sendo o centro essencial do "eu", a identidade de uma pessoa. Em contrapartida, na concepção sociológica, a identidade do sujeito se forma através da relação deste com outras pessoas, da interação de valores, sentidos, símbolos e cultura dos mundos habitados pelo sujeito. A identidade, nesta concepção, preenche o espaço entre o interior e o exterior, entre o mundo pessoal e o mundo público:

A identidade (...) costura (...) o sujeito à estrutura. Estabiliza tanto os sujeitos quanto os mundos culturais que eles habitam, tornando ambos reciprocamente mais unificados e predizíveis (HALL, 1998, p.10).

Ocorre que na globalização esta idéia de identidade unificada e estável tem sido fragmentada, apresentandose não mais como uma única identidade mas como uma composição de várias identidades, algumas vezes contraditórias ou não resolvidas. Para Ortiz (1985), as identidades que compunham as paisagens sociais "lá fora" e asseguravam as necessidades objetivas da cultura estão entrando em colapso diante das mudanças estruturais e institucionais. Pois, mais do que um processo de transformação social e cultural, a globalização representa a materialização de um paradigma que toma corpo a partir do momento em que um novo insumo assume papel de 
"fator-chave" no desenvolvimento das forças produtivas: a informação.

Para Castells, embora tenha sempre desempenhado papel crucial para a economia, torna-se, agora, o próprio produto do processo produtivo (CASTELLS, 1999, p.89). Nesse sentido, a "nova relevância desse fenômeno antigo" (cf. WERSIG e NEVELING, 1975; FREIRE, 2001; FREIRE, 2004) trouxe à tona questões sobre a natureza da informação, sua conceituação científica e os benefícios que pode trazer ao indivíduo no seu relacionamento com o mundo em que vive. Na perspectiva de Barreto, a informação está ligada à produção de conhecimento no indivíduo, sendo definida

como agente mediador na produção do conhecimento, [qualificando-se] em forma e substância, como estruturas significantes com a competência de gerar conhecimento para o indivíduo e seu grupo (BARRETO, 1994, p.4).

Estas "estruturas significantes" podem ser construídas por meio de ações políticas e técnico-científicas, no contexto da produção e transferência de estoques de informação primordiais para a produção do conhecimento. Nestes termos, "a informação é qualificada como um instrumento modificador da consciência do homem e de seu grupo" (BARRETO, 1994, p.3).

Abordando a questão da informação na sociedade globalizada, González de Gómez (1997) destaca a necessidade de situar os acontecimentos e processos (culturais, organizacionais, produtivos, políticos) em diferentes planos de integração, considerando a complexidade dos nós [links] que entrelaçam o local e os mundos externos, em todas as suas manifestações. Em decorrência, as ações dos atores sociais que trabalham com a informação devem atuar de modo a promover os fluxos de informação em todos esses diferentes planos. Isto significa não somente promover o acesso a redes de informação globais para atores locais, mas também estabelecer conexões entre os espaços locais e globais, com dois tipos de procedimentos: (a) extrativo, de modo que os atores locais se apropriem das informações disponíveis na rede; (b) produtivo, para que os atores locais confirmem sua presença argumentativa, econômica e política nos espaços das redes globais (GONZÁLEZ DE GÓMEZ, 1997).

Para Albagli, a relevância da cultura local na globalização está no seu papel de integração das especificidades:

... a partir do potencial integrativo do novo padrão tecnológico, o local redefine-se, ganhando em densidade comunicacional, informacional e técnica no âmbito das redes informacionais que se estabelecem em escala planetária." [Pois] a dimensão cultural do local atua na globalidade como um fio invisível que vincula os indivíduos ao espaço, marcando uma certa idéia de diferença ou de distinção entre comunidades (ALBAGLI, 1999, p.186-87).

Assim, o local constitui-se em suporte e condição para as relações globais. "É nele que a globalização se expressa concretamente e assume especificidades" (ALBAGLI, 1999, p.189). Podemos dizer que é nesse sentido que as culturas nacionais atuam como fontes principais de identidade cultural, pois a cultura nacional contribui para "unir" as diferenças numa única identidade. Assim, embora as formas da identidade cultural não estejam impressas em nossos genes, pensamos nelas como se fizessem parte da nossa natureza essencial. E sendo a cultura nacional uma das principais fontes da identidade cultural, falar sobre esta implica, antes, falar sobre aquela: "As pessoas não são apenas cidadãos/ãs legais de uma nação; elas participam da idéia da nação tal como representada em sua cultura nacional" (HALL, 1998, p.49).

Trabalhando com informação na perspectiva da cultura, Marteleto entende que cultura e informação "são conceitos fenômenos interligados pela sua própria natureza" (MARTELETO, 1995, p.90). A cultura funcionaria como uma memória que ao conservar e reproduzir artefatos simbólicos e materiais de geração em geração, torna-se a depositária da informação social. Neste sentido, "torna-se o primeiro momento de construção conceitual da informação, como artefato, ou como processo que alimenta as maneiras próprias do ser, representar e estar em sociedade" (MARTELETO, 1995, p.91). Dessa forma, a socialização da cultura (linguagem, estética, visão de mundo, valores, costumes) assume papel relevante para a democratização do acesso e uso da informação. Numa leitura antropológica da informação, seu processo de construção como objeto de estudo só se complementa quando se levam em conta, concretamente, as estruturas materiais e simbólicas de um dado universo cultural e as relações práticas e representações dos sujeitos, cada vez mais mediadas por um modo informacional e competente de ser e estar em sociedade. Desse modo, podemos dizer que à medida que a informação adquire relevância para a produção social, cresce a responsabilidade social do campo científico dedicado ao seu estudo, organização e transferência (FREIRE, 2001). 
É nesse sentido que propomos, no projeto Janelas da Cultura Local: Quissamã, RJ,* a realização de uma ação informacional fundamentada nas potencialidades das novas tecnologias de processamento e comunicação da informação, que para González de Gómez (2004) podem ser vistas "tanto [como] condição quanto [um] campo de ex-perimentação de novas práticas de informação" (GONZÁLEZ DE GÓMEZ, 2004, p.57). Também para Castells,

...as novas tecnologias não são simples ferramentas a serem aplicadas, mas processos a serem desenvolvidos. Usuários e criadores podem tornar-se a mesma coisa. Desta forma, os usuários podem assumir o controle da tecnologia, como no caso da Internet. Segue-se uma relação muito próxima entre os processos sociais de criação e manipulação de símbolos (a cultura da sociedade) e a capacidade de produzir e distribuir bens e serviços (forças produtivas) (CASTELLS, 1999, p.50-51).

Em decorrência dessa proximidade entre os processos culturais e produtivos, na sociedade contemporânea as tecnologias da informação e da comunicação não são apenas instrumentos técnicos no sentido tradicional, mas "feixes de propriedades ativas", algo tecnologicamente novo e diferente, pois se antes as tecnologias

serviam como instrumentos para aumentar o alcance dos sentidos (braço, visão, movimento etc)", agora "ampliam o potencial cognitivo do ser humano (seu cérebro/mente) e possibilitam mixagens cognitivas complexas e cooperativas (ASSMANN, 2000, p.6).

[As novas tecnologias] participam ativamente do passo da informação para o conhecimento. [O que] está acontecendo [é] um ingresso ativo do fenômeno técnico na construção cognitiva da realidade. Doravante, nossas formas de saber terão um ingrediente (...) derivado da nossa parceria cognitiva com as máquinas que possibilitam modos de conhecer anteriormente inexistentes (ASSMANN, 2000, p.13. Grifo nosso).

Neste contexto, uma "parceria cognitiva" se estabelece entre o ser humano e as máquinas inteligentes, de modo

\footnotetext{
* Em desenvolvimento no Ibict, com apoio do CNPq (modalidades $\mathrm{PQ}$ e APQ). Participam como pesquisadores convidados os doutores Gustavo Henrique de Araújo Freire e Vânia Maria Rodrigues Hermes de Araújo; como pesquisadoras colaboradores os mestres Bruno Macedo Nathansohn, Carmelita do Espírito Santo, Nanci Ferreira e Paula Martinez Mello. Participam, também, os especialistas Cristina Gáudio Teixeira e Ricardo Siqueira Neves. O texto original do projeto está disponível em: www.isafreire.pro.br. Pesquisa.
}

que termos como "usuário" não mais expressariam essa relação cooperativa adequadamente, uma vez que o papel das tecnologias de informação e comunicação

...já não se limita à simples configuração e formatação, ou, se quiserem, ao enquadramento de conjuntos complexos de informação. (...) Em resumo, as novas tecnologias têm um papel ativo e coestruturante das formas do aprender e do conhecer. Há nisso, por um lado, uma incrível multiplicação de chances cognitivas, que convém não desperdiçar, mas aproveitar ao máximo (ASSMANN, 2000, p.11).

É nesse quadro que "as políticas públicas podem fazer a diferença"*, de modo a favorecer o crescimento de uma sociedade da informação onde todos tenham "acesso a uma quota parte mínima dos novos serviços e aplicações" das tecnologias digitais de informação e comunicação (ASSMANN, 2000, p.15). Por isso mesmo, a democratização do acesso às tecnologias digitais de informação e comunicação deveria ser vista como elemento fundamental nas políticas inclusão social, de modo a ajudar as populações economicamente carentes a se beneficiarem das vantagens do progresso tecnológico, reforçando o caráter democrático da sociedade da informação.

\section{O DESAFIO DA INCLUSÃO DIGITAL NO BRASIL}

Em junho de 2003, o IBGE divulgou a Síntese de Indicadores Sociais de 2002, na qual esta desigualdade a que aludimos aparece como a característica mais marcante na sociedade brasileira. Apesar de alguns índices como saúde, educação e condições de domicílio apresentarem melhoras, "ainda é grande a diferença entre o topo e a base de nossa pirâmide socioeconômica" (REVISTA INTELIGÊN-CIA EMPRESARIAL, 2003, p.3). Esta situação se agrava quando observamos que está aumentando a distância entre os "providos" e os "desprovidos digitais", tanto em nível internacional quanto em nível local:

A chamada brecha digital preocupa não apenas porque a diferença de renda entre providos e desprovidos de

* Ainda mais na sociedade da informação, "entendida como aquela em que o regime de informação [ver nota 18] caracteriza e condiciona todos os outros regimes sociais, econômicos, culturais, das comunidades e do Estado", como esclarece González de Gómez (1999), uma vez que "a centralidade da comunicação e da informação produziria a maior dispersão das questões políticas da informação, perpassada e interceptada por todas as outras políticas: as públicas e as informais, as tácitas e as explícitas, as diretas ou indiretas". (GONZÁLEZ DE GÓMEZ, 1999 p.110). 
tecnologia digital tende a aumentar numa época de forte inovação tecnológica, mas pela oportunidade de diminuir esta desigualdade pelas vias dos ganhos dos mais pobres. Existem poucos diagnósticos e debates no contexto brasileiro sobre o binômio inclusão/exclusão digital. (...) A discussão raramente envereda pelo acesso às tecnologias pelo lado do (...) usuário pobre (...) É preciso desenvolver tecnologias para o uso da tecnologia da informação no combate à pobreza e à desigualdade (NÉRI et al., 2003. p.4).

Embora essas tecnologias não representem uma solução mágica para o complexo problema da desigualdade, sem dúvida "constituem [atualmente] uma das condições fundamentais da integração na vida social” (SORJ, 2003, p.15). Nesse sentido, as ações de inclusão digital devem ser consideradas relevantes no conjunto de políticas públicas de inclusão social, uma vez que, segundo Lévy, seria papel das tecnologias de informação e comunicação "promover a construção dos coletivos inteligentes, nos quais as potencialidades sociais e cognitivas de cada um [possam] desenvolver-se e ampliar-se de maneira recíproca" (LÉVY, 2000, p.193).*

As ações para inclusão digital tornaram-se especialmente relevantes depois que a Pesquisa Nacional por Amostra de Domicílios (Pnad) mostrou que apenas 12,5\% da população brasileira dispõem de acesso a computador em casa, mas os domicílios com altos percentuais de acesso digital estão localizados, em sua maioria, no Sudeste urbano, principalmente na Região Metropolitana de São Paulo. Com relação à Internet, segundo o Ibope eRatings (citado por RONDELLI, 2003b), o número de usuários domiciliares no Brasil cresceu 0,7\% em janeiro de 2003, atingindo 7,5 milhões de pessoas, aumentando também o número de horas navegadas em 7,5\% em relação a dezembro de 2002. Contudo, a presença na Web brasileira esteve concentrada nos sites de 'Carreira e Emprego', visitados por 1,4 milhão de internautas, $18,8 \%$ do total de usuários ativos, e 'Notícias e Informações', visitados por 3,2 milhões de internautas. Para Rondelli, "estes são indicadores de que a Internet no Brasil vai se firmando cada vez mais como um importante canal de serviços e mídia para os integrantes das classes A e B ..." (IBOPE E-RATINGS citado por RONDELLI, 2003b).

\footnotetext{
* Nesse sentido, em 2005 o Ibict liderou o Movimento de Acesso Livre à Informação, por meio do "Manifesto Brasileiro de Apoio ao Acesso Livre à Informação Científica", com o objetivo de "mobilizar a comunidade científica e a sociedade brasileira em geral para se universalizar e democratizar a informação em ciência e tecnologia ..." (SUAIDEN, 2005, citado por PINHEIRO, 2006).
}

Néri et al. relacionaram políticas de inclusão digital e Lei de Moore*, com o objetivo de "subsidiar o entendimento de campanhas de doação de computadores" para grupos economicamente desfavorecidos, partindo da premissa de que o "analfabetismo digital, ao afetar a capacidade de aprendizado, a conectividade e a disseminação de informações, gera conseqüências virtualmente em todos os campos da vida do indivíduo" (NÉRI et al., 2003, p.5). Entretanto, concordamos com Rondelli, quando lembra que "computadores conectados em rede é o primeiro [passo] mas não é o suficiente para se realizar a (...) inclusão digital” (RONDELLI, 2003a). À medida que permitem que se estabeleçam relações "descentralizadas e horizontalizadas" entre produtores e consumidores de informação e conhecimento, as mídias digitais facilitam a ambos permutar suas funções e papéis sociais, ora como produtores, ora como consumidores dos processos e conteúdos que circulam na mídia digital. Por isso mesmo, processos de inclusão

só ocorrem se a ampliação do acesso à qualquer uma das mídias existentes for acompanhada da inserção dos indivíduos em um universo cultural e intelectual mais rico que os motivem a utilizá-las (RONDELLI, 2003a).

Também para Lazarte, os elementos necessários para inclusão não devem contemplar apenas o acesso físico à infra-estrutura e a conexão em rede e computadores, mas, especialmente, a capacitação das pessoas para utilizar estes meios de comunicação da informação e, principalmente, para criar a "possibilidade de uma incorporação ativa no processo todo de produção, compartilhamento e criação cultural", os chamados "conteúdos" (LAZARTE, 2000, p.51). Nesse sentido,

a forma de se proporcionar este acesso deve estar integrada às condições locais existentes, em termos de suas organizações, tanto quanto em seus referenciais culturais. Centros de produção, criação e compartilhamento cultural (e de acesso à rede) devem estar integrados a associações comunitárias, centros religiosos, igrejas etc. (LAZARTE, 2000, p.48).

Entretanto, embora este seja um problema socialmente significativo, Néri et al. assinalam que "existem poucos

\footnotetext{
* Segundo essa lei, nos últimos 30 anos a unidade de potência dos computadores tem dobrado a cada 18 meses. Nesse cenário, a alta obsolescência tecnológica dos computadores levaria à possibilidade de doação de equipamentos computacionais em bom estado a grupos sociais economicamente carentes (NÉRI et al., 2003).
} 
diagnósticos e debates no contexto brasileiro sobre o binômio inclusão/exclusão digital. [Mas] A discussão raramente envereda pelo acesso às tecnologias pelo lado do (...) usuário pobre ...”. (NÉRI et al., 2003, p.5). Neste contexto trazemos as proposições de Araújo sobre o problema, quando destaca que

... o verdadeiro desafio [é] construir ferramentas [tecnologias intelectuais*] e sistemas mais eficazes, não só para gerenciar informação, mas, também, para facilitar ao ser humano a transformação da informação em conhecimento e, conseqüentemente, em ação na sociedade. (ARAÚJO, 2001, p.11)

Entretanto, como fazê-lo? Castells nos dá uma pista, quando observa que o problema da inclusão digital vai além do desenvolvimento tecnológico:

A questão crítica é mudar (...) para o aprendizadode-aprender, uma vez que a maior parte da informação [estará] on-line e o que realmente [será] necessário é a habilidade para decidir o que procurar, como obter isso, como processá-lo e como usá-lo para a tarefa específica que provocou a busca de informação. Em outras palavras, o novo aprendizado é orientado para o desenvolvimento da capacidade educacional de transformar informação e conhecimento em ação** (cf. Dutton, 1999). (CASTELLS, 2003, p.103)

Ele lembra nossa responsabilidade social nesse processo, quando afirma que:

ainda que não saibamos o bastante sobre as dimensões sociais e econômicas da Internet, sabemos [que] a melhoria de nossa condição dependerá do que as pessoas fizerem, inclusive você e eu (CASTELLS, 2003, p.107).

\footnotetext{
* Adotamos o modelo de Lévy, considerando 'tecnologias intelectuais' tanto "as formas de expressão simbólica (que, p.ex., evoluíram das narrativas míticas às equações quânticas)" quanto "as tecnologias de informação em si mesmas (p.ex., a escrita em tabuinhas de barro, as iluminuras medievais, a imprensa e os computadores). Segundo o autor, "essas tecnologias intelectuais situam-se fora dos sujeitos cognitivos, como este computador sobre minha mesa ou este livro em suas mãos. Mas elas também estão entre os sujeitos como códigos compartilhados, textos que circulam, programas que copiamos, imagens que imprimimos e transmitimos por via hertziana. (...). As tecnologias intelectuais estão, ainda, nos sujeitos, através da imaginação e da aprendizagem". (LÉVY, 1994, p.31. Grifo nosso).

** Sobre o conceito de "conhecimento em ação" no campo da ciência da informação, ver: WERSIG, 1993; FREIRE, 1995; ARAÚJO e FREIRE, 1999.
}

Contudo, a nosso ver depende não somente de nossa ação no mundo, mas, especialmente, da nossa própria conscientização sobre o poder transformador da informação:

[Pois] se a informação é a mais poderosa força de transformação do homem, [o] poder da informação, aliado aos modernos meios de comunicação de massa, tem capacidade ilimitada de transformar culturalmente o homem, a sociedade e a própria humanidade como um todo (ARAÚJO, 1994. p.84).

E aqui se revela outro pressuposto na nossa abordagem: a relevância do papel dos profissionais da informação na sociedade contemporânea, muito menos no que diz respeito à competência no uso das tecnologias intelectuais e digitais, do que em relação a uma visão social de mundo*. Nesse sentido a questão remeteria à aposta de Pascal, retomada por Goldmann como possibilidade para a realização futura de uma sociedade engajada na complexa tarefa de produzir a si mesma por meio da interação de seus diversos grupos e, neles, dos indivíduos:

Para que o homem viva como homem, ele deve engajar sua vida sem reservas, na esperança de um valor autêntico cujo sinal mais claro é que ela é realidade.É o paradoxo fundamental da condição humana: a união dos contrários, a união do espírito e da matéria [Em Georg Lukàcs,] reaparece essa idéia de que ser homem significa engajar sem reservas sua existência na afirmação eternamente improvável de uma relação possível entre o dado sensível e o sentido, entre Deus e a realidade empírica atrás da qual ele se esconde, relação (...) que não se pode demonstrar e na qual, entretanto, é necessário engajar toda sua existência.** (GOLDMANN, 1979, p.53).

Como muitos dos visionários que acreditam numa utopia

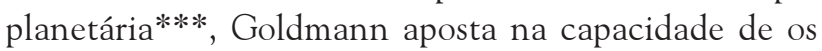
indivíduos construírem uma verdadeira comunidade humana no futuro, fundamentando a reflexão que vimos realizando sobre o papel dos profissionais que atuam no campo da informação: contribuir, de um lado, para ampliar a teia mundial de comunicação da informação e, de outro, para diminuir a "infoexclusão", aumentando as possibilidades de livre acesso aos estoques de

\footnotetext{
* A propósito, ver: FREIRE, 2004.

** O texto original data de 1954. Sobre a "aposta" de Goldmann no campo da ciência da informação, ver Apêndice em FREIRE, 2001.

*** Em sua História da utopia planetária Mattelart (2002) cita, entre outros, Américo Vespúcio, Thomas More, Montaigne, Bacon, SaintSimon, Paul Otlet e Henri La Fontaine. À lista, acrescentamos Pierre Lévy com sua inteligência coletiva. Ver FREIRE, 2005.
} 
informação. Nesse sentido, Lévy (2000) destaca que "o principal projeto arquitetônico do século XXI será imaginar, construir e organizar o espaço interativo e móvel do ciberespaço" (LÉVY, 2000, p.26) e o Ministério da Ciência e Tecnologia publicou o Livro Verde da Sociedade da Informação no Brasil, com as metas de implementação do Programa Sociedade da Informação.

O Livro Verde contempla um conjunto de ações para impulsionar a sociedade da informação no Brasil, em todos os seus aspectos: ampliação do acesso, meios de conectividade, formação de recursos humanos, incentivo à pesquisa e desenvolvimento, comércio eletrônico, desenvolvimento de novas aplicações. A finalidade do Programa é lançar as bases de um projeto de amplitude nacional, para integrar e coordenar o desenvolvimento e a utilização de serviços avançados de computação, comunicação e informação e de suas aplicações na sociedade. Destarte, uma pesquisa nas páginas brasileiras na Internet e uma visita ao sítio virtual Portal de Inclusão Digital [www.idbrasil.gov.br] nos permite avaliar o nível de interesse do governo e da sociedade civil nos processos de inclusão digital.

É nesse quadro que o presente projeto se insere como contribuição ao estudo dos processos sociais de produção e comunicação da informação como proposição de ações de inclusão digital com a transferência de tecnologias intelectuais e digitais para redes de ensino públicas, em municípios brasileiros.

\section{BREVE HISTÓRIA DE QUISSAMÃ, RJ*}

A escolha da cidade de Quissamã, localizada na região norte do Estado do Rio de Janeiro, justifica-se pelo contexto socioeconômico-cultural no qual ela se encontra inserida. Trata-se de uma pequena cidade localizada na região norte do estado do Rio de Janeiro, com população de aproximadamente 14 mil habitantes, distribuída numa área de $660 \mathrm{~km}^{2}$.

As origens da relevância política e social de Quissamã podem ser encontradas na sociedade escravista, base do seu núcleo histórico e cultural. A pecuária, primeira base econômica, cedeu lugar à monocultura açucareira, na metade do século XVIII. Houve grande desenvolvimento, que foi quebrado com a estagnação econômica gerada pelo endividamento das fazendas da região, durante a crise de 1929. Nessa ocasião a produção açucareira foi monopolizada pelo Engenho Central de Quissamã, primeiro engenho central construído na

* Usamos como base o texto de Espírito Santo, 2003.
América Latina em 1877. A partir da criação do Programa Pró-Álcool e da descoberta do petróleo na Bacia de Campos, o município obteve crescimento acelerado, que culminou no seu desmembramento do município de Macaé, do qual fazia parte como distrito. A emancipação ocorreu em 12 de junho de 1988 e a criação do município foi oficializada em 4 de junho de 1989. Desde então, Quissamã tem sido apontada como a economia mais promissora do estado do Rio de Janeiro, apresentando indicadores de ensino público significativos.*

O crescimento econômico ao mesmo tempo em que garante a manutenção da prosperidade do município, concorre, também, para a importação de padrões culturais, mediados não somente pelos meios de comunicação de massa, como também pela indústria cultural local. Assim, apesar do grande potencial histórico e cultural da região, a cultura local vem perdendo importância junto à maioria da população, que tem adotado padrões de manifestação da cultura importada. Embora este seja um fenômeno que ocorre na maioria das pequenas cidades brasileiras, a questão tornou-se relevante para a administração municipal de Quissamã, que entende que este fato concorre para o enfraquecimento da identidade cultural local:

Não queremos que nossa população deixe de ouvir ou ver o 'Tchan', mas é importante que eles tenham conhecimento e consciência de nossa riqueza cultural, que nos garante uma identidade própria**.

Este argumento ilustraria o que ocorre por ocasião dos grandes eventos que marcam acontecimentos importantes na sociedade local. Nestas ocasiões não se observariam mais manifestações típicas da cultura local, refletindo um certo 'apagamento' [esquecimento] da população em relação às manifestações da cultura popular do município, "principalmente na população de jovens e crianças" (ESPÍRITO SANTO, 2002, depoimento da comunidade). Acrescente-se, também, que em Quissamã

\footnotetext{
* Em janeiro de 2003, o jornal O Globo publicou extensa reportagem sobre as precárias condições do ensino público no interior do estado do Rio Janeiro. Em um cenário geral preocupante, Quissamã apresenta taxa de freqüência escolar maior do que a estadual: 91,61\%. A rede de ensino pública local tem 17 escolas de ensino fundamental e 400 vagas no ensino médio. A prefeitura atende 600 jovens que não conseguem vaga na escola pública com bolsas de estudo em escolas privadas (O GLOBO, jan. 2003).

** Depoimento da secretária de Educação e Cultura de Quissamã [2002], professora Ana Alice de Barcelos Silva, à pesquisadora Carmelita do Espírito Santo. (ESPÍRITO SANTO, C. Notas de pesquisa de campo, 2002. Grifo nosso).
} 
localiza-se talvez a única manifestação do fado* africano em território brasileiro, manifestação cultural que estaria correndo o risco de desaparecimento, por não ter se difundido na população mais jovem**.

Pensar sobre o registro da manifestação cultural de uma comunidade, que representa relevante aspecto da identidade cultural local, consiste em esclarecer, antes de mais nada, em qual concepção de cultura a identidade cultural está apoiada nossa abordagem. De acordo com Hall (1998), uma das formas com que se pode narrar a identidade é através da cultura nacional, mas a proposta configurada neste projeto busca mostrar um dos aspectos da cultura nacional bastante mencionado na literatura, qual seja, o folclore***.

A relação entre folclore e identidade cultural local pode ser evidenciada em ações e eventos. Podemos citar, como relevante, a Conferência Mundial sobre o Patrimônio Cultural da Humanidade, promovida pela Unesco, em Istambul, que culminou com a Declaração em Defesa do Patrimônio Imaterial e da Diversidade Cultural dos Povos, **** aprovada em setembro de 2002. Nesse texto, os ministros da Cultura de 72 países destacam a importância das ações educativas ou informacionais, no sentido de garantir a transmissão do patrimônio cultural imaterial dos povos, fator indispensável à preservação das identidades culturais de comunidades, regiões ou

\footnotetext{
* Travassos esclarece que este 'fado' "nada tem em comum com a canção portuguesa de mesmo nome. [Trata-se de uma] Dança de origem afro-brasileira, era praticada no Brasil colonial, cuja coreografia incluía estalidos de dedos, palmas e sapateados. Em Quissamã designa sempre um conjunto de danças desencadeadas. A festa deve começar por uma cantiga de reis, seguida de louvações ao dono da casa e sua família" (TRAVASSOS, 1991, p.167). A manifestação cultural do fado não tem data fixa nem pertence a nenhum ciclo do calendário religioso. $\mathrm{O}$ fado é considerado, pelos participantes, como uma dádiva de Deus distribuída por seus dançadores.

** Em decorrência do trabalho de Espírito Santo (2003), em uma das escolas participantes (da rede pública) foi criado um grupo de fado onde jovens estão apre[e]ndendo esta relevante manifestação cultural da comunidade.

*** De acordo com Brandão, o domínio do que é folclore é tão grande quanto o domínio da cultura: "folclore é tudo o que o homem do povo faz e reproduz como tradição...” (BRANDÃO, 1994, p.24). Desta forma, por vezes, é visto como sinônimo de cultura popular e vice versa, como entende Câmara Cascudo ao definir folclore como "a cultura do popular tornada normativa pela tradição" (CÂMARA CASCUDO, 1960 citado por BRANDÃO, 1994). Há diferenças importantes entre folclore e cultura popular e para alguns estudiosos o folclore é mais conservador e a cultura popular mais progressista: "uma manifestação é folclórica quando além de ser popular, constituise em sobrevivência. $\mathrm{O}$ folclore seria, portanto, uma manifestação do passado no presente". (CÂMARA CASCUDO, 1960 citado por AYALA e AYALA, 1987, p.15).

**** Disponível em www.metodista.br/unesco/JBCC/jbcc192.htm
}

países. São considerados como objetos de estudos do folclore:

- as narrativas tradicionais, como os contos populares, os mitos, lendas e estórias de adultos e de crianças, as baladas, romances e canções;

- os costumes tradicionais preservados e transmitidos oralmente, de uma geração a outra;

- os códigos sociais de orientação da conduta, as celebrações cerimoniais populares;

- os sistemas populares de crenças e superstições ligados à vida e ao trabalho, englobando o saber da tecnologia rústica, da magia, da feitiçaria, das chamadas ciências populares; os sistemas e as formas populares de linguagem, seus dialetos, ditos e frases feitas e advinhas" (BRANDÃO, 1994, p.28).

Espírito Santo (2003) realizou sua pesquisa para construção de hipertexto sobre a cultura local em Quissamã, com apoio da Secretaria Municipal de Educação e Cultura (Semec), tendo o folclore como tema, por escolha dos parceiros locais (dirigentes e técnicos da Semec, dirigentes, coordenadores e professores das escolas envolvidas na pesquisa). A amostra da pesquisa foi constituída pelas escolas que oferecem ensino de $1^{\mathrm{O}}$ e $2^{\circ}$ graus em Quissamã, com alunos da última série do $1^{\underline{O}}$ grau e das três séries do $2^{\circ}$ grau, além de professores (de história e de português), diretores, supervisores e coordenadores. A pesquisa mostrou que o tema da identidade cultural se coloca como possibilidade de inclusão digital, favorecendo o treinamento nas tecnologias intelectuais para produção de conteúdos que representem valores, tradições e saberes da cultura local.

Neste contexto se inserem as tecnologias de organização, processamento, comunicação, busca e recuperação de informações relevantes para um dado grupo de usuários na sociedade, que por sua vez podem vir a produzir seus próprios estoques de informação. No seu trabalho, Espírito Santo (2003) destaca o papel relevante da ciência da informação na socialização da informação "através de sua capacidade de intermediar a realização de uma ação informacional que contempla um contexto comunitário, onde produtores e usuários de informação participaram de forma ativa e igualitária" (ESPÍRITO SANTO, 2003, p.67). E com a régua e o compasso desse 
campo científico, traçamos nossa rota para abrir as janelas da cultura local no ciberespaço*.

\section{O CAMINHO E AS COORDENADAS}

No presente projeto, propomos o desenvolvimento de ações de informação, de forma participativa, com vistas a promover a competência de pessoas da comunidade em tecnologias intelectuais de informação, incluindo a construção de um hipertexto digital sobre a cultura local, que será o eixo motivacional e operatório da pesquisa.

O termo "pesquisa-participante" foi criado por pesquisadores norte-americanos e europeus envolvidos com projetos de intercâmbio com países de Terceiro Mundo, na área de ciências sociais. O processo envolve contato permanente entre os participantes da pesquisa (pesquisadores e usuários), sendo que o primeiro momento é dedicado ao conhecimento preliminar da realidade, de modo a identificar o que Goldmann (1970) denomina "informação prévia". Desta ação, resulta a formação de um grupo de trabalho que, no segundo momento, identifica, na comunidade, os "temas geradores" do conteúdo do hipertexto. Os temas levantados e sua pertinência são discutidos pelo grupo, à medida que a interação entre pesquisadores e usuários da informação favorece a reflexão crítica sobre os temas, que se "abrirão" na direção de outros temas. Desta forma, uma "informação prévia" será gradualmente incorporada ao hipertexto em construção, e o processo trabalha, ao mesmo tempo, a "consciência real" e a "consciência máxima possível" dos participantes da pesquisa (FREIRE, 1998).

Por sua vez, a escolha da pesquisa-ação traduz a tentativa de abordar a comunicação da informação como ação transformadora, no sentido que lhe atribui Araújo (1994), criando espaço para intervenção empírica em uma dada situação. A pesquisa-ação supõe uma participação e uma forma de ação planejada que atinja os vários elementos das atividades humanas - diretamente relacionada à presente proposta, à medida que viabiliza a ação coletiva pautada pela resolução de problemas e por objetivos de transformação.

\footnotetext{
* Palavra de origem americana, "empregada pela primeira vez pelo autor de ficção científica William Gibson, em 1984, no romance Neuromancien. O ciberespaço designa ali o universo das redes digitais, como lugar de encontros e de aventuras (...) nova fronteira econômica e cultural. [Hoje,] designa menos os novos suportes de informação do que os modos originais de criação, de navegação no conhecimento e de relação social, por eles propiciados". (LÉVY, 2000, p.104. Destaques no original).
}

$\mathrm{Na}$ América Latina a pesquisa-ação também foi formulada em termos de "pesquisa participante", sendo utilizada como instrumento no contexto das populações carentes, "com seus problemas educacionais, culturais ou de consciência política” (THIOLLENT, 1997, p.21), e no Brasil tem sido pensada e aplicada no contexto das organizações e instituições. Aa pesquisa-ação "consiste essencialmente em acoplar pesquisa e ação em um processo no qual os atores implicados participam, junto com os pesquisadores, para chegarem interativamente a elucidar a realidade em que estão inseridos..." (THIOLLENT, 1997, p.15). Nessa perspectiva, entendese por "ator" qualquer grupo de pessoas dispondo de certa capacidade de ação coletiva consciente em um contexto social delimitado, podendo designar tanto os grupos informantes no meio de uma organização quanto os grupos formalmente constituídos, e "participação" é encarada como propriedade emergente do processo e não como a priori.

Buscando uma visão sintética, Dubost (1987) examinou várias concepções de pesquisa-ação vinculadas à tradições norte-americanas e européias, formulando sua própria definição como "ação deliberada visando a uma mudança no mundo real, realizada em escala restrita, inserida em um projeto mais geral e submetida a certas disciplinas para obter efeitos de conhecimento e de sentido" (DUBOST, 1987, citado por THIOLLENT, 1997, p.35). No presente projeto integramos à abordagem de Dubost a visão cooperativa de Desroche (1990), que define a pesquisa-ação como uma pesquisa

... na qual os autores de pesquisa e os atores sociais se encontram reciprocamente implicados: os atores na pesquisa e os autores na ação. No limite, esses dois papéis tendem a identificar-se em uma só instância de operação. (...) na pesquisa-ação os atores deixam de ser simplesmente objeto de observação, de explicação ou de interpretação. Eles tornam-se sujeitos e parte integrante da pesquisa, de sua concepção, de seu desenrolar, de sua redação e de seu acompanhamento. (DESROCHE, 1990, citado por THIOLLENT, 1997, p.36) 


\section{Isa Maria Freire}

Serão identificados o regime de informação* do município de Quissamã, RJ e os elementos constitutivos da identidade cultural local. $O$ projeto será conduzido como uma rede de pesquisa e desenvolvimento de tecnologias intelectuais e digitais, acompanhado de um programa de capacitação e treinamento de pessoas da comunidade no uso dessas tecnologias. Serão realizados seminários de pesquisa-ação para discussões teóricas, metodológicas e operacionais da pesquisa, bem como seminários de divulgação científica para apresentação dos resultados do projeto para a comunidade local, a comunidade científica e a sociedade em geral, em consonância com as premissas do processo participativo na pesquisa e do acesso livre à informação produzida sobre e a partir do projeto.

Estamos apostando nas possibilidades interativas das tecnologias digitais e buscando oportunidades para inclusão de comunidades na sociedade da informação por meio da valorização de sua identidade cultural abrindo janelas para o virtual na realidade local.

\footnotetext{
* González de Gómez se refere ao "regime de informação" como uma "dimensão estrutural, que produz um ex antes a toda ação de transferência de informação, independente de nossos desejos e competências singulares. (...) Um 'regime de informação' se desdobra [em] um conjunto mais ou menos estável de redes formais e informais nas quais as informações são geradas, organizadas e transferidas de diferentes produtores, por muitos e diversos meios, canais e organizações, a diferentes destinatários ou receptores de informação, sejam estes usuários específicos ou públicos amplos". (GONZÁLEZ DE GÓMEZ, 2004, p.61)
}

\section{REFERÊNCIAS}

ALBAGLI, S. Globalização e espacialidade: o novo do local. In: GLOBALIZAÇÃO \& inovação localizada: experiências de sistemas locais no Mercosul. Brasília: Instituto Brasileiro de Informação em Ciência e Tecnologia: Ministério da Ciência e Tecnologia, 1999.

ARAUjO, V. M. R. H. de. Miséria informacional: o paradoxo da subinformação e superinformação. Inteligência Empresarial, n. 7, abr. 2001.

- Sistemas de recuperação da informação: nova abordagem teórico-conceitual. 1994. Tese (Doutorado Comunicação e Cultura)Escola de Comunicação da UFRJ, Rio de Janeiro, 1994.

ASSMANN, H. A metamorfose do aprender na sociedade da informação. Ciência da Informação, v. 29, n. 2, p. 7-15, maio/ago. 2000.

AYALA, M.; AYALA, M. I. N. Cultura popular no Brasil: perspectiva de análise. São Paulo: Ed. Ática, 1987.

BARRETO, A. de A. A eficiência técnica e econômica e a viabilidade de produtos e serviços de informação. Ciência da Informação, v. 25, n. 3, 1996.

n. 4 , out./dez. 1994.

A questão da informação. São Paulo em Perspectiva, v. 8, BRANDÃO, C. R. O que é folclore. 12. ed. São Paulo: Brasiliense, 1994.

. Pesquisar-participar. In: BRANDÃO, C. R. (Org.). Pesquisa participante. 6. ed. São Paulo: Brasiliense, 1986.

BRASIL. Ministério da Ciência e Tecnologia. Sociedade da informação no Brasil: livro verde. Brasília, 2000.

CASCUDO, L. da C. Dicionário do folclore brasileiro. São Paulo: Global, 1960.

CASTELLS, M. A era da informação: economia, sociedade e cultura. In: A sociedade em rede. São Paulo: Paz e Terra, 1999.

- A galáxia da Internet: reflexões sobre a Internet, os negócios e a sociedade. Rio de Janeiro: Jorge Zahar, 2003.

DESROCHE, H. Entreprendre d'apprendre: d'une autobiographie raisonnée aux propjets d'ue recherche-action. Paris: Ed. Ouvrières, 1990.

DUBOST, J. Lintervention psycho-sociologique. Paris: PUF, 1987.

DUTTON, W. H. Society on the line: information politics in the digital age. New York: Oxford Press University, 1999.

FOLKCOMUNICAÇÃO: tradições culturais da humanidade serão preservadas pela Unesco. Jornal Brasileiro de Ciências da Comunicação, São Paulo, v. 5 n. 192, 04 out. 2002.

FREIRE, G. H. de A. Comunicação da informação em redes virtuais de aprendizagem. 2004. Tese (Doutorado em Ciência da Informação)CNPq/IBICT - UFRJ/ECO, Rio de Janeiro, 2004.

. A construção de instrumento para comunicação de informação sobre saúde. 1998. Dissertação (Mestrado em Ciência da Informação)CNPq/IBICT - UFRJ/ECO, Rio de Janeiro, 1998.

FREIRE, I. M. A utopia planetária de Pierre Lévy: uma leitura hipertextual d'a inteligência coletiva. Perspectivas em Ciência da Informação, v. 10 n. 2, p. 132-139, jul./dez. 2005.

- A responsabilidade social da ciência da informação e/ou o olhar da consciência possível sobre o campo científico. 2001. Tese (Doutorado em Ciência da Informação) - CNPq/IBICT - ECO/UFRJ, Rio de Janeiro, 2001.

GOLDMANN, L. Dialética e cultura. Rio de Janeiro: Paz e Terra, 1979. 


\section{Acesso à informação e identidade cultural: entre o global e o local}

Importância do conceito de consciência possível para a informação. In: O CONCEITO de informação na ciência contemporânea. Rio de Janeiro: Paz e Terra, 1970.

GONZÁLEZ DE GÓMEZ, M. N. Novas fronteiras tecnológicas das ações de informação: questões e abordagens. Ciência da Informação, v. 33, n. 1, 2004.

Política e gestão da informação: novos rumos. Ciência da Informação, v. 28, n. 2, p. 109-110, maio/ago. 1999.

A globalização e os novos espaços da informação. Informare, v. 3, n. 1/2, 1997.

HALL, S. A identidade cultural na pós-modernidade. 2. ed. Rio de Janeiro: DP\&A, 1998.

IANNI, O. Teorias da globalização. 4. ed. Rio de Janeiro: Civilização Brasileira, 1997.

INSTITUTO BRASILEIRO DE GEOGRAFIA E ESTATÍSTICA IBGE. Disponível em: <www.ibge.gov.br>. Acesso em: 2006.

LAZARTE, L. Ecologia cognitiva na sociedade da informação. Ciência da Informação, v. 29, n. 2, 2000.

LÉVY, P. A inteligência coletiva: por uma antropologia do ciberespaço. 3. ed. São Paulo: Ed. Loyola, 2000.

. As tecnologias da inteligência: o futuro do pensamento na era da informática. Rio de Janeiro: Ed. 34, 1994.

MATTELART, A. História da utopia planetária: da cidade profética à sociedade global. Porto Alegre: Ed. Sulina, 2002.

MARTELETO, R. M. Cultura, educação, distribuição social dos bens simbólicos e excedente informacional. Informare, v. 1, n. 2, 1995.

NERI, M. et al. Lei de Moore e políticas de inclusão digital. Revista Inteligência Empresarial, n.14, jan. 2003.

O GLOBO, Rio de Janeiro, jan. 2003.

ORTIZ, R. Cultura brasileira e identidade nacional. São Paulo: Brasiliense, 1985.

PINHEIRO, L. V. R. La red sócio-técnica para acceso a la libre información en la Internet y acciones integradoras, renovadoras e innovadoras. In: TALLER DE DIRECTRICES PARA EL MANIFESTO DE INTERNET/INTERNET MANIFESTO
WORKSHOP GUIDELINES, 2006, Santiago, Chile. Anales... Chile: IFLA/FAIFE- UNESCO, 2006. p. 24-25.

- "Educação da sensibilidade", informação em arte e tecnologias para inclusão social. Inclusão Social, v. 1, n. 1, p. 51-55, 2005.

REVISTA INTELIGÊNCIA EMPRESARIAL, n. 7, abr. 2001.

RONDELLI, E. Quatro passos para a inclusão digital. Disponível em: $<$ www.icoletiva.com.br $>$. Acesso em: 2003a.

. Mídia, informação e conhecimento. Disponível em: <www.icoletiva.com.br>. Acesso em: 2003b.

SANTO, C. do Espírito. "Quissamã somos nós": pesquisa participante para construção de hipertexto sobre identidade cultural. 2003. Dissertação (Mestrado Ciência da Informação) - CNPq/IBICT - UFRJ/ ECO, Rio de Janeiro, 2003.

SORJ, B.Brasil@povo.com: a luta contra a desigualdade na Sociedade da Informação. Rio de Janeiro: Jorge Zahar Ed.; Brasília, DF: Unesco, 2003.

SUAIDEN, E. Apresentação. In: INSTITUTO BRASILEIRO DE INFORMAÇÃO EM CIÊNCIA E TECNOLOGIA - IBICT. Manifesto brasileiro de apoio ao acesso livre à informação científica. Brasília: IBICT, 2005.

TRAVASSOS, E. Música: o fado. In: MARCHIORI, M. E. P. et al. Quissamã. Rio de Janeiro: Secretaria de Cultura/Prefeitura Municipal, 1991.

THIOlLENT, M. Metodologia da pesquisa-ação. 10. ed. São Paulo: Cortez Ed., 2000.

. Pesquisa-ação nas organizações. São Paulo: Atlas, 1997.

WERSIG, G. Information Science: the study of postmodern knowledge usage. Information Processing and Management, v. 29, n. 2, 1993.

; NEVELING, U. The phenomena of interest to information science. The Information Scientist, v. 9, n. 4, 1975.

ZEMAN, J. Significado filosófico da noção de informação. In: O CONCEITO de informação na ciência contemporânea. Rio de Janeiro: $\mathrm{Paz}$ e Terra, 1970. 